\title{
A DESSIMBOLIZAÇÃO DO FAROESTE
}

\section{THE WESTERN DESSIMBOLIZATION}

\author{
Ciro Inácio Marcondes \\ UnB - Universidade de Brasília
}

\begin{abstract}
Resumo: O faroeste é um gênero cinematográfico que sempre primou por dualidades bem claras, procurando distinguir a civilização e a selvageria através de arquétipos que cumprem funções bem estabelecidas no projeto civilizatório norte-americano. Rastros de Ódio, filme de John Ford de 1956, reinaugura a tradição do faroeste revertendo esses princípios e estabelecendo espaços simbólicos diferenciais a partir de motivos abstratos como o conflito, a fuga e a busca. Nessa nova configuração, o que se pensa dominante na verdade é dominado por um discurso velado, que fala através de um lócus anterior. Índios, cowboys, mestiços, mexicanos e outros se misturam em instâncias em que, pensando estar cultivando um determinado discurso, na verdade projetam a fala do outro. Este ventriloquismo étnico é o que desloca as verdadeiras fronteiras simbólicas com que esses personagens se deparam, exibindo uma América que se identifica pela negatividade.
\end{abstract}

Palavras-chave: pós-colonialismo; faroeste; John Ford; estudos culturais; teoria cinematográfica.

Abstract: Western is a cinematographic genre that have always focused on well distinguished dualities, looking for separation between civilization and wilderness using archetypes that obey well established functions in the north-american civilizing project. John Ford's The Searchers (1956) transcends the western tradition by reverting these principles and establishing symbolic differential spaces from abstract motives like conflict, escape and search. In this new configuration, what is thought as dominant, in truth, is dominated by a hidden speech that talks through an ancestral locus. Indians, cowboys, half-castes, mexicans and others blend themselves when thinking about cultivating a determined speech, when in fact they are projecting the other's speech. This ethnic ventriloquism is the force that moves the true symbolic frontiers with which these characters have contact, exhibiting an America that identifies itself specially through negativity.

Keywords: post-colonialism; western; film theory; John Ford; cinematographic studies.

\section{1 - Introdução: o western e Rastros de Ódio}

Texas, 1868. Três anos após a guerra de secessão, uma família de rancheiros divide suas experiências agrestes com seus vizinhos. Vivem a típica adaptatividade dos pioneiros, em uma terra seca e isolada, seguindo seus costumes cristãos de acordo com as possibilidades do território. Eis que um agente disruptor aparece, um ponto na planície de terra seca, que se aproxima andando a cavalo. Trata-se de Ethan Edwards, irmão de Aaron, chefe da família que o recebe de braços abertos. Ethan lutou ao lado dos confederados na guerra civil. Derrotado, desapareceu e andou a esmo por três anos. Não se sabe qual foi seu paradeiro. Traz consigo ouro novo - dinheiro incerto que pode ter sido roubado de um banco - e muitas incógnitas. Suas maneiras são embrutecidas, rudes, destiladas em um humor cáustico, agressivo. É um 
cowboy, mas não um herói. Sua presença traz gravidade à casa. Sua afeição pelas crianças da família não impede que se instaure um clima de ruptura. Martha, esposa de Aaron, cheira sua roupa: parece se lembrar de tempos passados. Não ficamos sabendo muito mais do que isso. Está aí montada uma situação de conflito. Aaron pergunta: "como estava a Califórnia"? Ethan responde, enigmático: "por que eu deveria saber"?

Este é apenas o início do enredo de Rastros de Ódio (The Searchers), filme de John Ford (1956) que participa da história do cinema justamente como uma espécie de ponto de virada na ética do western, realizando uma profunda explanação da dubiedade relacionada à necessidade do herói, às culturas em conflito e à formação da "identidade" norte-americana. Ford, de fato, filma uma fábula (já que o chamado "super-western", termo cunhado por André Bazin, não estava mais preocupado em esconder sua natureza mítica sob supostas histórias de aventura, mas sim em esconder sua natureza juvenil em histórias verdadeiramente míticas) apoiando-se sobre três conceitos básicos, que dão o tom a todo e qualquer tipo de discussão a respeito do filme. São conceitos-chave, primitivos, arquetípicos, que servem de ponte para a ressimbolização de valores que o filme, se não promove, ao menos põe em questão de maneira urgente. São eles a busca, o conflito e a fuga.

O primeiro conceito é o mais entranhado em nós mesmos. Buscamos algo, em nossa vida. E geralmente buscamos voltando. Às vezes, andando em círculos. Dentro de um panorama sócio-cultural, reviramos, escavamos, mas encontramos apenas pistas, sinais, que remetem a outros símbolos - símbolos de dubiedade. A busca é, portanto, uma ação inevitável, perene e incompleta. Um hiato. O segundo conceito nos remete a uma dialética: identificamos o conflito nos termos da enunciação. Procuramos sínteses, respostas, resoluções. Mas o conflito é uma resolução, ele não precisa implicar algo mais. O conflito é o próprio conhecimento que ele busca. Como se fosse um fim, e não um meio, o conflito esboroa-se quando tenta ser elucidado. O espaço do conflito é um espaço de abertura, de conhecimento, de possibilidades cognitivas, interpretativas. Rastros de Ódio é a própria epistemologia do conflito. Por fim a fuga, que é um dos termos do conflito com a busca. Quando se aplica o conflito à busca, foge-se. Tudo escapa, tudo desliza, nada é conhecido, a não ser o conflito e a fuga em si mesmos.

O resultado de tudo isso não é tanto uma frustração, já que a materialidade de um conhecimento iluminista vai-se desfazendo, mas um renascer de saberes mais arcaicos, mais sensoriais, provendo esses hiatos e esses conhecimentos secretos, fugidios, a própria fuga. Parece um triunfo da intuição e uma ode ao não-estabelecido, àquilo que não pode ser visto, tocado, catalogado. Ford foi sensível ao ressaltar esses aspectos em uma narrativa tão tradicional. Com uma força vulcânica, o diretor incorpora esses conceitos na forma de fábulas humanas, trazendo para dentro dos homens os cenários majestosos das torres de pedra do monument valley. Toda a dimensão épica do cenário, da história e das relações humanas naquelas terras, onde o conflito se espalha como o vento, é trazida para uma captação muito particular; uma forma sensível e um aperto grande em nossas almas.

Como se fizesse uma grande radiografia de todos os estratos de seu filme, Ford dessimboliza o faroeste, reduz seu caráter a ícones arcaicos. Viaja através dos espaços de conflito que estabelece e foge. Foge das respostas, mas alcança a intuição. Rastros de Ódio fala sobre culturas em conflito, e permite refletir (mas jamais chegar a uma conclusão) sobre as dimensões dos pontos em contato entre as culturas humanas, sua (não)formação e sua interação cheia de toques que se desfazem. É um filme simples, mas implica nada menos que um conhecimento selvagem, uma ruptura na forma com que conhecemos as influências entre culturas e saberes humanos. 
Mas por que busca, conflito e fuga? Bem, o retorno de Ethan (John Wayne) não é a única situação de conflito. Algumas cabeças de gado das famílias aparecem mortas em um local não muito distante do rancho. Ethan e o Reverendo Clayton (Ward Bond), membro dos Texas Rangers (uma milícia não-governamental encarregada de escorraçar os índios das proximidades), além de alguns outros homens, incluindo Martin Pawley (Jeffrey Hunter), um mestiço adotado pelos Edwards, vão a campo aberto verificar o que aconteceu, deixando Martha (Dorothy Jordan), Aaron (Walter Coy) e seus três filhos (Ben, Lucy e Debbie) em casa. É o tempo que uma tribo de índios comanches, autores da cilada, necessita para invadir a casa, saquear e massacrar a família, matando os homens e Martha, retirando seus escalpos e seqüestrando as filhas do casal.

Entram em cena, portanto, os índios, clássicos protagonistas do western, sempre vistos como um inimigo a ser batido, um entrave à chegada dos colonizadores que, através de seu ideológico "destino manifesto", consideram-se um povo privilegiado, com autorização divina para conquistar e exaurir aquelas novas terras. O que se segue é uma longa jornada de cinco anos que Ethan e Martin enfrentam atrás dos raptores de Debbie (Natalie Wood) (Lucy é morta - e estuprada - no caminho), através de 2 mil milhas por todo o Texas, além de chegar a Oklahoma, Albuquerque, Novo México e até mesmo ao próprio México, do outro lado da fronteira (como assinala Buscombe, 2004, p.31). Em uma simbologia clara da dimensão épica da busca, eles atravessam invernos rigorosos, calores infernais, batalhas situadas entre rios, massacres por parte da cavalaria yankee, bandidos na estrada, além de expandirem seus contatos culturais com índios e mexicanos e desenvolverem uma conflituosa troca intersubjetiva, que vai transformando-os, de maneira sutil porém intensa, até o término do filme.

No final, Debbie é recuperada - mesmo tendo sido aculturada - e trazida de volta ao seio da família. Ethan, o racista, o monstruoso cowboy torpe, de índole violenta, assassina e rude, que chega a investir contra Debbie em determinado momento do filme ("viver como os comanches é não estar vivo"), aparentemente se redime. Mas não entra de volta na casa. A cena final é antológica. Após todos os integrantes da família adentrarem a casa junto com Debbie, a porta, sozinha, se fecha, com Ethan indo embora, "enquadrado" por sua moldura. O que pode significar isso?

O western parte de situações de conflito ainda mais drásticas do que todas as que já foram apresentadas na ficção cinematográfica. Em seu clássico Enterrem Meu Coração na Curva do Rio (2006), o historiador Dee Brown apresenta inúmeros relatos de índios, extraídos de reuniões oficiosas com representantes do governo dos Estados Unidos. Em sua maioria, as grandes tribos do sudoeste dos Estados Unidos foram massacradas pelos exércitos confederados e yankees que, durante a guerra civil, não queriam vê-los por perto, tentando despachá-los, todos juntos, para áreas reservadas distantes de suas terras de origem. Antes e depois da guerra, os massacres foram justificados pela construção de estradas, ferrovias ou até mesmo pela dizimação dos búfalos, principal fonte de alimentos dos nativos. Ainda que muitas etnias tivessem membros saqueadores e "invasores" (o território não era deles?), a maioria das tribos queria apenas continuar vivendo de acordo com seus costumes e em suas terras de origem. Muitas delas não se importavam com a convivência com o homem branco, desde que não fossem massacrados por eles. Brown registra um comovente relato do chefe Cadette, dos Navajos, por volta de 1861, em Santa Fé, após a crescente investida do general Carleton, yankee interessado nos minerais das terras dos índios (já que não havia mais confederados para combater naquele lugar): 
Vocês são mais fortes que nós. Lutaríamos com vocês se tivéssemos rifles e pólvora; mas suas armas são melhores que as nossas. Dêem-nos armas iguais e nos deixem livres, que também os combateremos; mas estamos abatidos; não temos mais ânimo; não temos provisões, nenhum meio de vida; suas tropas estão em toda parte; nossas fontes e poços estão ocupados ou vigiados por seus jovens. Vocês nos tiraram do nosso último e melhor baluarte, e não temos mais ânimo. Façam conosco o que bem entenderem, mas não se esqueçam de que somos homens e bravos. (BROWN, 2006, p. 34).

O espaço do western é e não é um espaço pós-colonial. Ele é - na medida em que, dentro da História, acontece após a independência dos Estados Unidos. Passa-se, portanto, após o período colonial "oficial". Mas ele não é propriamente pós-colonial, no sentido em que os filósofos do pós-colonialismo tradicionalmente encaixam o termo. Seu espaço é o da guerra constante. Não apenas uma guerra econômica, cultural, étnica, representacional. Os habitantes do oeste americano do século XIX - e em especial os índios - estão envolvidos em conflitos armados capazes de dizimar suas populações. $\mathrm{O}$ espaço do western é também o espaço da guerra civil e o da expansão para o grande oeste: espaços pontuados pelo armamentismo e pela expansão militarista. A relação entre índios e brancos não pode ser vista como uma simples (e complexa) relação de voz e supressão de voz. O subalterno aqui não apenas não pode falar; não pode viver. É um espaço colonial, ainda que não-declarado, porque as vozes privilegiadas não têm apenas o poder simbólico, têm o poder militar e o usam contra as vozes suprimidas - as vozes dos índios. Isso não impede, porém, que nesse espaço de guerra e subjugação de uma cultura por outra através da via militar haja trocas simbólicas. Mais do que isso, não impede que haja, nesse espaço de conflito, fuga e busca.

E é essa a nossa tese sobre Rastros de Ódio: a constituição de semânticas culturais que se alternam, mesmo em um espaço colonial, ou seja, o emprego de uma retórica pós-colonial dentro de um espaço de colonialismo. Talvez seja, ainda mais do que um colonialismo propriamente dito, a apropriação de terras através da expulsão e dizimação de seus habitantes naturais. Os yankees e confederados não estavam muito interessados em estabelecer de fato uma relação colonial com os índios. Preferiam acabar com eles ou isolá-los em um espaço onde eles não pudessem interferir em seus interesses expansionistas.

O oeste americano do século XIX é, portanto, um espaço de conflito ideológico, cultural, territorial e militar. E o conflito é um fim em si mesmo. O relato de Cadette é significativo, pois mostra a não-solução do problema, que é aparentemente o modo de pensar com o qual o indígena norte-americano teve de se habituar: não há como resolver esse conflito. Estão abatidos, estão sem ânimo. É um conflito não-resolvido, e que nunca se resolverá. Torna-se uma epistemologia, uma ordem do conhecimento torpe e ruidosa, difícil e massacrante. Mas é assim que o contato cultural vai se instaurando, como um vírus que se aloja, consome e transforma. O não-discurso, a não-solução passa a ser, portanto, a viabilidade. Os índios acham, no entanto, uma fissura, um lócus de enunciação nãoidentificado, e se escondem nele, para nunca mais serem encontrados. $\mathrm{O}$ western, um gênero adaptativo, é também um discurso que se esconde.

André Bazin, o grande teórico que inspirou a nouvelle vague, pensou o western como um deflagrador de mitos - uma enorme narrativa simbólica e arquetípica que desfila tipos diversos que flutuam nas possibilidades imaginativas da história humana. O maniqueísmo inclui a possibilidade de valores totais, a presença explícita de salvadores e vítimas, a presença quase exclusiva de seres mitológicos, todos disfarçados na história. Está aí o pontochave do western: sua argumentação exaustiva que entrelaça mito e história, como se fossem coisas intercambiáveis. Há, portanto, no western, uma fuga constante, um deslizar crônico, de 
uma instância a outra, sem que jamais estejam juntas, pois são instâncias incomunicáveis. Esta constante realimentação em fontes que estão em constante conflito constituem a ontologia do gênero. "Ces attributs formels auxquels on reconnaît d'ordinaire le western ne sont que les signes ou les simboles de sa réalité profonde que est le mythe. Le western est né de la rencontre d'une mythologie avec un moyen d'expression" (BAZIN, 2002, p. 219).

Não é de admirar, portanto, que o western perca sua aura mitológica (ou a evidencie a ponto de não mais poder se confundir com a história) com a chegada do chamado superwestern a partir do final da Segunda Guerra. Nesse momento crucial, a filmografia do gênero passa a rever seus valores ontológicos, procurando ser a antítese (mais um conflito) daquilo que representou até então. Filmes como Matar ou Morrer (High Noon, 1952, de Fred Zinneman), Os Brutos Também Amam (Shane, 1953, de George Stevens), Flechas Ardentes (Broken Arrow, 1950, de Delmer Daves) e Winchester 73 (1950, de Anthony Mann) revisitam a mitologia sob os auspícios de uma psicologia tortuosa, além de um forte veio sociológico, que acabam pulverizando a realimentação enriquecedora que fizera do western dos primórdios e do western clássico uma fórmula tão consagrada. Chegara a hora de remodelar os espaços de representação que sempre se reciclavam no gênero e quebrar os círculos hermenêuticos que viciavam - com vivacidade, reconheçamos - as relações estabelecidas entre mito e história que fundaram a retórica do gênero.

\begin{abstract}
Em outras palavras, se a esfera do poder social de determinada cultura está submetida à mudança histórica, e se esta não é apenas uma função dinâmica interna de qualquer cultura, mas também, e sobretudo, uma função de fatores heterogêneos (tais como contaminações espaciais que vêm de fora, na forma de conquistas militares ou dominação política ou econômica), então o círculo hermenêutico nunca estará fechado (MOREIRAS, 2001, p.26)
\end{abstract}

Era o momento de uma escapada, uma fuga perpetuada por uma nova busca. A partir daí, vozes sublimadas, lugares de enunciação desconhecidos e exóticas relações de troca e miscigenação emergem à superfície do western, criando um padrão de reflexão antes impensável para a simples vinculação imaginativa entre poder do Estado e poder do indivíduo (BAZIN, 2002), que o gênero veiculava anteriormente. O conflito e a sua não-solução (fuga) passam a ser dominantes. Uma lógica do paradoxo se estabelece. Aquilo que desaparece, que escapa, que não é enunciado, passa a ser o condutor dessas formas de representação. Rastros de Ódio é o expoente máximo dessa leva de super-westerns. Talvez por isso podemos pensar que a fuga de Ethan, no final do filme, é também uma forma de não-conclusão. A porta se fecha, mas o filme está em aberto. Ethan nada decidiu. O sincretismo anárquico da personagem nunca se resolve. Escapa, como os comanches que ele persegue (e aí está um elo claro entre a diegese do filme e sua simbologia), e se evapora, como seu passado e seu futuro.

\title{
2 - Flutuações semânticas e valores diferenciais
}

Ethan e Martin perseguem comanches Nawyecky, "aqueles que andam em círculos". De fato, os índios se escondem tanto que nada sabemos sobre eles, absolutamente. Como em um western tradicional, Ford os representa basicamente em cenas de guerra, exceção feita à cena em que Martin e Ethan fazem escambo com alguns comanches não-Nawyecky, quando Martin acaba se casando acidentalmente com a índia Look (Beulah Archuletta). Os índios, portanto, basicamente fogem. Fogem porque são apresentados no escuro: Ford os inclui no filme na primeira cena noturna. Apenas Scar (Henry Brandon), o chefe, aparece. Ele tem um rosto identificável, diferentemente dos outros comanches (com exceção de Look), mas é um 
rosto que também esconde: suas falas são contidas, pouco é revelado sobre ele. Sabe-se, no filme, apenas que dois de seus filhos foram mortos pelo homem branco.

Ford procura reequilibrar as simbologias culturais, mas não revela absolutamente os índios. Nada sabemos, também, de Debbie: ela se esconde, igualmente. A tão festejada presença de Natalie Wood no filme é reservada apenas para a meia hora final. E ela tem poucas falas. Em determinado momento, diz: "este é meu povo", mas contraditoriamente escolhe ir com os brancos. Esconde seus laços indígenas. Ou revela às sombras, como é nas sombras que primeiro aparecem os índios. "For someone who has spent years as a Comanche captive, she looks remarkably well-groomed. But the film is not really interested in details of Debbie's life with the Indians. We don't look to the Western for ethnography" (BUSCOMBE, 2004, p.58). Sua representação alterna falas pontuais, significativas e silêncios expressivos. Debbie tem mais falas quando é mostrada na infância, pois aí o discurso é da cultura dominante, civilizada, que possui uma representação verbal e oral poderosa, histórica, representativa.

Os índios dominam um outro estrato da comunicação, e isso tem uma via dupla: ao mesmo tempo em que são identificados por seus gritos de guerra e contatos onomatopaicos (conforme Ethan os reconhece), expondo a expressão dos urros e dos transes, sua nãoverbalização é um símbolo de sua desaparição, que também tem orientação dupla: a desaparição real dos índios, com o massacre de suas etnias, e a desaparição supra-real, com a não-representação usual que tiveram que transformar em um meio de vida, conforme vimos no relato de Cadette. Outro chefe indígena da mesma época, desta vez apache, também traz um relato interessante a Dee Brown: "Essa gente de Tucson escreveu para os jornais e contou sua história. Os apaches não têm ninguém para contar sua história" (BROWN, 2006, p.194).

De fato, mesmo com o filme de Ford, o livro de Brown ou mesmo este trabalho, os índios continuam sem ninguém para contar sua história. Não porque não existam pessoas que se esforçam para transcrever e divulgar seus relatos, mas sim porque seus próprios relatos se tornaram não-histórias. Tornaram-se, na verdade, discursos sombrios, catacreses, como diria Gayatri Spivak (DE LA CAMPA, 1999, p.18), "claim for which no referent exist". O discurso indígena tornou-se um discurso do sujeito sem objeto, uma fuga epistemológica. Não é possível recuperar o discurso indígena tal qual se deseja em uma "recuperação" tradicional. É preciso pensar em locais de enunciação pulverizados, que se situam em frestas, como se fosse um pensamento em negativo, resultado da subtração feita pelas falas que simbolizam o discurso hegemônico. Por isso é que, mesmo sendo Rastros de Ódio um filme anti-racista, os índios continuam não podendo falar porque, à sua maneira, Ford também concorda que os subalternos da cultura dominante não podem, e não sabem, se representar.

Mas o ato de se esconder não se restringe aos índios. Ethan, o verdadeiro aculturado, tem como força-motriz o seu passado desaparecido. Em todos os momentos em que parece que algo será revelado, Ford insere uma interrupção, como se fosse uma pulsão bloqueadora. Saber sobre a formação de Ethan é metafórico em relação à formação da identidade da cultura híbrida norte-americana: tenta-se buscá-la, mas ela esvai-se porque, e essa parece ser a tese inconsciente de Ford, o presente não revela exatamente o passado. Não da maneira como poderíamos pensar. $\mathrm{O}$ western distancia-se, definitivamente, da história e recai de maneira derramada sobre o pensamento mítico. A busca de Ethan é, evidentemente, uma busca por si mesmo, mas também pela identidade do homem norte-americano, que presencia deslocamentos culturais que se rearranjam sem que se perceba, transformando figuras aparentemente "normais" em monstros de um hibridismo não-resolvido. 
Dito sem sutileza: se o sujeito mestiço busca rearmonizar sua perturbada ordem discursiva, submetendo-a à urgência de uma identidade tanto mais forte quanto se sabe quebradiça, o migrante como que deixa que se derrame sua linguagem, contaminando-a ou não, sobre a superfície e nas profundidades de uma deriva, em cujas estações se armam intertextos vulneráveis e efêmeros, descompassados, porque sua figuração primeira é a de um sujeito sempre deslocado (POLAR, 2000, p.133)

O triângulo híbrido do filme, Ethan-Martin-Debbie, revela isso com clareza. Ethan é um homem branco, cristão, um suposto herói (um cowboy), pertencente a uma família honesta, que se desgarra, perde uma guerra, envolve-se em um passado nebuloso, conhece os costumes e a língua dos índios, além de ter uma proximidade com os mexicanos, e torna-se um errante que busca entender seu próprio sincretismo. Ele vê em Debbie um sincretismo semelhante, já que ela é uma verdadeira aculturada, e passa a buscá-la de maneira obsessiva, como se uma imagem especular pudesse revelar qualquer coisa sobre a identidade de quem não é o simulacro. Mas Debbie é de um sincretismo diferente. Ela vive com os índios, mas volta à civilização. Ethan, que aparentemente os odeia, refugia-se na selvageria. Por fim, Martin, que é mestiço, jamais se interessa realmente pela cultura indígena. Seu affair é com Laurie (Vera Miles), filha dos vizinhos dos Edwards, uma moça abertamente racista que carrega em si todos os valores esperados pela mulher no oeste: ela é a única personagem que não busca e nem foge. Ela apenas espera. Martin quer buscar Debbie e impedir mais hibridismos entre índios e brancos, como se carregasse uma culpa pela sua origem cherokee. Sua busca é pela restituição da ordem que foi rompida com a sua própria origem. Não à toa, ele rejeita (ainda que em uma cena revestida de humor) sua esposa índia, tratando-a, como era de esperar, como um objeto exótico. Disfarçado em uma integridade valente e heróica, Martin carrega em si um vampirismo às avessas, uma necessidade de reincidentemente impedir sua origem, um Sísifo moderno (já que falamos de mitos), que também carrega sua própria epistemologia. Mais um não-discurso, uma negação ambulante, uma voz que se ouve apenas nas entrelinhas.

O que significa, portanto, em Rastros de Ódio, ser índio, ser branco e ser mestiço? Ford propõe uma solução que se alterna entre o simplismo radical e uma complexidade crescente. Ainda no início do filme, quando Brad (Harry Carey Jr), o filho dos vizinhos dos Edwards (e namorado de Lucy), ainda está com eles na busca pelos comanches, perseguindoos inutilmente, profere uma frase significativa: "se são humanos, uma hora têm que parar". Ford chega, portanto, a questionar a humanidade (não apenas simbólica) dos índios. Será que, dentro de um círculo cultural tão distante e complexo, os índios poderiam ser incluídos na mesma categoria ontológica que o resto da humanidade? O que significa, por exemplo, Ethan atirar nos olhos de um cadáver comanche, esperando que ele nunca alcance o céu, vagando eternamente como um espírito no mundo dos mortais? Por que, se os índios não são humanos, todos os personagens brancos do filme carregam em si marcas de aculturação, como se estivessem todos, efetivamente, dentro do mesmo espaço simbólico da disputa étnica?

E o que significa essa disputa? Parece que o conflito se torna a retórica maior, a narrativa-mestre do western. Como categorias que não se misturam, mas se substituem em grande velocidade e se inter-relacionam de maneira muito próxima, as semânticas culturais de Rastros de Ódio partem do conflito como uma maneira de sublimar suas incongruências. Não interessa a resolução do conflito, mas sim a semântica do conflito. Ou a ontologia do conflito. A própria (e equivocada) tradução do título do filme para o português evidencia, muito curiosamente, esse fim para o qual se dirigem todas as ações do filme: o ódio é um signo do conflito. Os personagens não apenas buscam. Buscam em conflito. Daí a resultante 
esquizofrenia de Ethan, que se assemelha aos índios por ter um discurso fragmentado. Tanto ele se identifica com seus rivais que passa a se comportar como eles, trazendo o escalpo de Scar após a morte do chefe indígena. O escalpo, curiosamente, foi introduzido na cultura indígena pelos espanhóis (BROWN, 2006, p.38), comprovando a idéia de que signos culturais flutuam em substituições mútuas, sempre de maneira especular e circular. O conflito, portanto, é o fator definidor da configuração do western, tanto em seus estratos mais profundos (conforme vimos demonstrando), quanto em suas formas mais elementares, como fala A.C. Gomes de Melo, (2004, p. 17-18),

O traço definidor do gênero é o conflito elementar entre civilização e selvageria. Este conflito básico é expresso através de uma variedade de oposições: Leste contra Oeste, cidade contra sertão, ordem social contra anarquia, indivíduo contra comunidade, inocência contra corrupção, pioneiro contra índio, professora rural contra dançarina de saloon, e assim por diante. A trajetória narrativa de todo e qualquer western aciona a oposição dominante civilização-selvageria, gerando um conflito - ou uma série de conflitos - que são constantemente intensificados até que o confronto climático se torne inevitável.

Ora, é claro que há uma enorme simplificação nessa assertiva. Afinal, civilização e selvageria são discursos de grande magnitude. São códigos-mestre, e podem ser submetidos e uma prática desconstrutiva. Como vimos, os elementos de semântica cultural que aparecem em Rastros de Ódio são micro-elementos. São culturas de fuga, de escape. Civilização e selvageria aparecem como simulacros, quando pensamos que esses termos estão dentro de cada um dos micro-elementos, alternando-se na velocidade do contato cultural. Portanto o confronto jamais é climático, mas sim imanente. O discurso do conflito não é o desenlace de uma situação dialética, já que ele existe antes da selvageria e da civilização. Há dois exemplos que, juntamente com a formação de Ethan, explicitam melhor a natureza desta relação. Há um personagem secundário na trama chamado Mose (Hank Worden), um ex-caçador de búfalos, amigo das duas famílias. Assim como Ethan, Mose conhece o costume dos índios e parece guardar em seu (também desconhecido) passado uma enormidade de experiências transculturais. A sublimação de seu passado se assemelha à de Ethan, na medida em que nada é revelado sobre o que não é presente, mas difere dele ao externar seus sentimentos.

Mose é um sujeito de comportamento estranho, que esperneia e grita, de fala enrolada e idiotizada, brincalhão e tratado como uma espécie de doente mental. Ele sempre guarda, entretanto, chaves e respostas para momentos cruciais da narrativa, como quando sabe que é preciso descansar os cavalos antes de ir atrás de Scar, ou quando revela a exata localização da tribo comanche. Como se adviesse da naïvité, sua sabedoria toca o pensamento mítico, que se confunde com a história dos índios. Não há nada de civilizado e tampouco de selvagem em Mose. Sua identidade é transcultural, em sua acepção mais profunda, porque consegue retornar ao passado-que-não-se-diz. Da mesma forma estão as moças aculturadas que Ethan encontra no acampamento dos yankees que acabaram de dizimar a tribo de Look, como a esposa de Martin: abobadas, reconfiguradas, são o símbolo de um presente que não precisa de passado. Estas são as que não mais buscam.

Se existe um tipo de "solução" para os diálogos de semântica cultural presentes em Rastros de Ódio, é unicamente o caminho do mito, justamente por suprimir o diálogo e aceitar o conflito como pavimento para uma nova forma de realização existencial. Poder-se-ia sugerir que, com o massacre dos índios pelos yankees e a morte de Scar no final do filme, a morte seria uma semântica possível para os índios, indicando uma solução radical para o conflito. 
Porém, como vimos na fala de Cadette, isso nem sempre se dá da mesma forma. A aproximação circular entre os termos civilização e selvageria não poderia ser melhor exemplificada do que na relação entre Ethan e Martin, o conflito maior e mais significativo do filme.

Logo no início, ficamos sabendo que a família de Martin foi assassinada, e quem o encontrou vivo foi Ethan. Quando Aaron tenta sensibilizar Ethan para esse fato, ele responde: "encontrei-o por puro acaso". Inicia-se aí uma relação estranha, já que Ethan rejeita a todo momento a companhia de Martin, tentando convencê-lo sempre a deixá-lo fazer a busca sozinho, como se buscar fosse uma possibilidade exclusiva daqueles que perderam sua origem, como Ethan, e não daqueles mestiços que têm sua origem registrada na pele, como Martin. Cornejo Polar, ao pensar o migrante (que seria Ethan) e o mestiço (que seria Martin), concebe-os em termos de "síntese" e "estratificação":

Certamente, a condição do migrante não desloca as características étnicas de índio ou mestiço, mas de certo modo pode englobá-las, como a outras, em termos de um processo tanto individual como coletivo, no interior de um processo que situa o movimento, e por conseguinte a história e sua aprumada influência, no primeiro plano. Afinal de contas, migrar é algo assim como ter nostalgia a partir de um presente que é ou deveria ser pleno de muitas instâncias e estâncias que se deixaram lá e então, um lá e então que logo se descobre que são o aqui da memória insone mas fragmentada, e o agora que tanto corre como se aprofunda, verticalmente, num tempo espesso que acumula sem sintetizar as experiências do ontem e dos espaços que se deixaram atrás e que continuam perturbando com raiva ou com ternura. (POLAR, 2000, p.130)

Ethan, como migrante, vive um presente pontuado por um passado fractal, que se manifesta de maneira pulsional, mas que raramente se apresenta efetivamente como passado. Já Martin, um mestiço que não se reconhece como tal, tem um pensamento purificado, sintético, e trabalha com grandes conceitos, que ordenam sua dimensão ontológica. A atração de Ethan pelos índios, entretanto, faz com que ele, mesmo relutante, acabe preservando a companhia de Martin até o fim do filme, ainda que, assim como faz com Debbie (a quem tenta matar e depois resgata), oscile entre momentos de agressividade (Ethan usa-o como isca para assassinar um bandido) e jocosidade (quando é brincalhão diante da ridícula situação do casamento de Martin). Martin, por sua vez, insiste em chamá-lo de "tio", até que Ethan lhe ordena que pare com isso. O maior momento de dubiedade identitária ocorre, entretanto, quando, ao discutirem sobre o paradeiro de Debbie, Martin insinua (em sua busca mitológica por seu paraíso cultural perdido) que ela é sua irmã, e Ethan retruca: "ela não é nada sua". É curioso perceber que Ethan enxerga Debbie como uma índia, e Martin, como uma branca. Enquanto o primeiro diz que a busca para reintegrá-la, mas na verdade procura uma integração com os índios, seus simulacros, o segundo diz que a busca para resgatá-la, mas procura de fato o extermínio de uma parte dela, justamente a parte que rejeita de si mesmo. Ethan-Martin, diria o clichê, são duas faces da mesma moeda, porém simbolizam mais do que isso: são a própria materialização da semântica maior do filme: busca, conflito e fuga.

Já no final, o mexicano Figueroa conduz Ethan e Martin ao acampamento comanche e este é o momento crucial para entendermos a significação última do filme. O encontro com Scar é bastante simbólico. Interpretado por um ator alemão (!), Scar é de uma altivez plastificada. Seu significado transcende sua representação. Ford focaliza-o em primeiro plano e faz um triplo raccord, mostrando também Ethan e Martin dessa forma. Estabelece-se aí uma 
dinâmica visual que prescinde das palavras: o filme todo, em todos os seus estratos complexos de inter-relações culturais, está contido nesses três planos. Pela primeira vez, Ethan usa um chapéu branco, símbolo tradicional do mocinho no western clássico. No resto do filme, está sempre com o chapéu preto do bandido. Há no encontro, portanto, uma harmonia conflituosa: a cena é carregada de muita tensão, mas equilibrada por esse paradoxo básico da retórica do conflito, da busca e da fuga: quando tudo é resolvido, ainda assim há conflito, porque categorias de semântica cultural não coexistem, mas se substituem mutuamente.

O branco, o índio e o mestiço, categorias estereotipadas, resolvem suas trocas de micro-estruturas com olhares e representações. Logo depois, uma sinfonia étnica se estabelece: insultos, provocações, olhares enviesados, bilingüismo. Eles entram na tenda e travam uma rápida, porém intensa, conversa sobre escalpos e mortes na família, e são surpreendidos pela silenciosa presença de Debbie, graciosamente vestida como uma índia. Martin e Ethan, tendo encontrado o objeto fugitivo de sua busca (apenas materialmente) preferem calar-se, não tanto pelo perigo que representaria qualquer manifestação, mas principalmente pelo momento holístico, ou seja, o equilíbrio entre as tensões culturais que são alimentadas em todo o decorrer do filme. Há equilíbrio apenas nas tensões, já que, como foi dito, o conflito nunca cessa. Figueroa, o mexicano, está ali como intérprete e mediador da dinâmica. Diferentes gradações de americanos se apresentam. Coexistem, apesar de não se misturarem, ou melhor, misturam-se, apesar de não coexistirem.

Ethan e os personagens principais de Rastros de Ódio representam, portanto, signos revertidos. Se o western clássico procurava criar uma antítese entre selvageria e civilização, com o cowboy sendo um intermediário entre esses conceitos, o super-western busca uma completa reversão de valores: o cowboy desiste (ainda que sem saber disso) de sua missão integradora, para tornar-se uma valise de plurivocalidade, às vezes representando o oposto daquilo que deveria ser. Daí decorre a quantidade de degenerados e freaks que vão influenciar todos os gêneros do cinema a partir dos anos 1960, como se o estranho e o incômodo fossem formas de representação mais fortes do que os discursos-mestre do maniqueísmo, da identidade e da diferença. Alberto Moreiras, em seu livro A exaustão da diferença (2001), propõe uma desarticulação dessas noções que, segundo ele, são segregacionistas e facilitam o escape de discursos hegemônicos. Identidade e diferença fariam parte de um projeto dual um conflito, portanto - porém detentor de um simplismo perigoso, que estabeleceria uma clara relação entre sujeito e objeto, afeita a articulações totalizantes. Moreiras prefere o dualismo hegemonia $\mathbf{x}$ subalternidade, fugindo da neutralidade asséptica e legitimadora das noções anteriores, para explicar a retórica do conflito pela natureza heraclitiana dos entrechoques culturais:

Mas a noção de modernidades alternativas não é, entretanto, uma noção exaustivamente culturalista: apenas constata o fato de que a história do capital e a história do que poderíamos chamar de poder social - entendido como o estado constitutivo da esfera simbólica em qualquer formação social - não coincidem e nem são idênticas (MOREIRAS, 2001, p. 14)

Existe, portanto, uma incompatibilidade entre discursos históricos que impossibilita traçar uma linha coerente para a formação "identitária" do cidadão norte-americano. Direções destoantes parecem conduzir os traços característicos dos norte-americanos que, mesmo no século XIX, já podiam ser identificados de acordo com uma lógica pós-colonial. O espaço ritual e político ao qual são submetidos os personagens, no encontro na tenda de Scar, revela uma grande potencialidade relacionada à diferença colonial (MIGNOLO, 2003), uma espécie 
de déficit entre o que significam as semânticas dos povos dos pontos de vista político, econômico e cultural. Um espaço colonial pressupõe esses déficits, e são justamente esses deslocamentos hegemônicos, como nos conta Moreiras, que nos permitem identificar locais de enunciação enraizados em buracos inseridos nas formas identitárias de verbalização da condição das populações mundiais. Ora, o espaço ritual é o único em que índio efetivamente tem a chance de se expressar. "Para cada filho morto meu, eu retiro muitos escalpos brancos", diz Scar. É uma fala rude, simples, mas uma forma de representação, embora minúscula, dentro de um espaço totalmente hegemonizado pela cultura branca.

O filme é completamente dominado pelas preocupações dos brancos. A fala de Scar é apenas uma pequena pista: os índios não podem falar, mas isso não significa que não existam. Estão fracos, como diz Cadette, mas são homens e bravos. Sua luta recrudesce em um tempo e um espaço diferenciais. Rastros de Ódio explicita bem o que significa a diferença colonial: a fala dos índios aparece através dos brancos. Quando Ethan busca sua origem no nomadismo dos índios, está manifestando a cultura indígena. O maior expoente da cultura norteamericana (o cowboy) é transfigurado em um totem a serviço da fala dos índios. Todos os amálgamas culturais presentes em Rastros de Ódio estão a serviço da cultura dos índios. É um pensamento fissural, liminar, origina-se das profundezas de um antidiscurso. Ford não fez um filme anti-racista porque criou um personagem odiosamente racista, mas justamente porque suprimiu por completo a representatividade dos índios, manifestando-a porém em todos os outros atributos culturais do filme. É uma não-fala que emerge, um não-discurso que contamina. Um pensamento propriamente liminar:

O pensamento liminar, como veremos, busca compensar a diferença colonial que a tradição colonial (sem ser unidirecional, como a globalização em nossos dias) tentava neutralizar como parte da ordem universal. No século 16, a diferença colonial articulava-se espacialmente. Ao se aproximar o fim do século 18 e o início do 19 , o critério de avaliação já não era mais a escrita, mas a história. "Os povos sem história" situavam-se em um tempo "anterior" ao "presente" (MIGNOLO, 2003, p.23).

Rastros de Ódio transforma radicalmente esse critério de avaliação, colocando os "povos sem história" no presente. Como suas histórias são um retrato da fuga, a busca por elas não passa de um encontro constante e reincidente com o presente. Trazendo à tona uma força mítica e um discurso diferencial, que permite encontrar fagulhas de culturas subalternas instaladas na própria cultura hegemônica, Ford realiza uma estética que transcende a simples noção de "formador da cultura norte-americana". Como espaço ao mesmo tempo colonial e pós-colonial, o oeste americano esteve submetido a uma transculturação rigorosa mas imperceptível, uma troca de valores simbólicos que se dá mesmo através da dizimação e do não-contato, como se os signos simplesmente flutuassem no ar e transformassem inimigos que nunca se vêem, pois ambos fogem. Há um diálogo semântico e cultural, portanto, mesmo em culturas que estão separadas por abismos como a guerra. Mas é um abismo enviesado que, como dizia Nietzsche, olha para dentro de você. Quando Ethan pega o escalpo de Scar ou atira nos olhos do cadáver comanche, ele não está apenas realizando uma vingança muito propriamente particular, utilizando os métodos dos índios contra eles mesmos, como se os quisesse fazer "provar do próprio remédio". E também não são apenas esses costumes indígenas que se tornaram um hábito mórbido e se instalaram dentro do modus operandi do homem branco, fenômenos de uma transculturação. Naquele momento, sim, é Ethan que é incorporado aos costumes, como se fosse ele mesmo um indivíduo, um objeto cultural, sendo trocado simbolicamente por aqueles sujeitos que são os costumes dos índios. É nesse 
momento, precisamente, que percebemos o discurso hegemônico se transformando no plano cultural, e vemos que histórias locais podem tornar-se histórias não mais globais, mas universais, por um breve momento. Arif Dirlik corrobora esta idéia (1998, p. 337):

One might suggest that, if a crisis in historical consciousness, with all it's implications for national and individual identity, is a basic theme of postcoloniality, then the first world itself is postcolonial. To the extent that the Euro-American self-image was shaped by the experience of colonizing the world (since the constitution of the Other is at once also the constitution of the Self), the end of colonialism presents the colonizer as much as the colonized with a problem of identity.

Rastros de Ódio, portanto, traça uma linha de história cultural que vai além dos simples referentes de identidade e diferença. Sua busca é por um tipo de representação que ignore o passado (dissolvido na não-história do subalterno, que sempre foge) e busque no presente as idiossincrasias dos discursos que vão se substituindo conforme os valores diferenciais vão se explicitando. Talvez seja essa, enfim, a única representação possível para o norte-americano: o debulhar de seu discurso hegemônico através das feridas de sua ostentação, de seus entre-lugares existenciais, de suas localizações perdidas. Buscar os Estados Unidos através do que não existe mais, do que não pode mais ser contado, do que não tem voz, mas se manifesta como espectro (tal qual os espectros que Ethan deseja ver andando na terra) que sombreia - e conduz - ainda, as semânticas culturais. O original para Rastros de Ódio é The Searchers. Não seria uma boa tradução Os Procuradores. Seria mais incisivo Os Buscadores. Busca-se. Ethan é a nação norte-americana buscando.

\section{Referências Bibliográficas}

BAZIN, André. Qu'est-ce que le cinema? 14.ed. Paris: Cerf-Corlet, 2002. BROWN, Dee. Enterrem meu coração na curva do rio. Porto Alegre: L\&PM, 2006. BUSCOMBE, Edward. The Searchers. London: British Film Insitute, 2004. (BFI Film Classics)

CORNEJO POLAR, Antonio. O condor voa. Literatura e cultura latino-americanas. Belo Horizonte: Ed. UFMG, 2000.

DE LA CAMPA, Román. Latinamericanism. Minneapolis: University of Minnesota, 1999. DE MATTOS, A. C. Gomes. Publique-se a lenda: a história do western. Rio de Janeiro: Rocco, 2004.

DIRLIK, Arif. The postcolonial aura. Third world criticism in the age of global capitalism. Boulder, Colorado: WestviewPress, 1998.

MIGNOLO, Walter. Histórias locais / projetos globais. Colonialidade, saberes subalternos e pensamento liminar. Belo Horizonte: Ed. UFMG, 2003.

MOREIRAS, Alberto. A exaustão da diferença. A política dos estudos culturais latinoamericanos. Belo Horizonte: Ed. UFMG, 2001. 
CASA, Vol.7 n.1, julho de 2009

\section{ANEXOS}
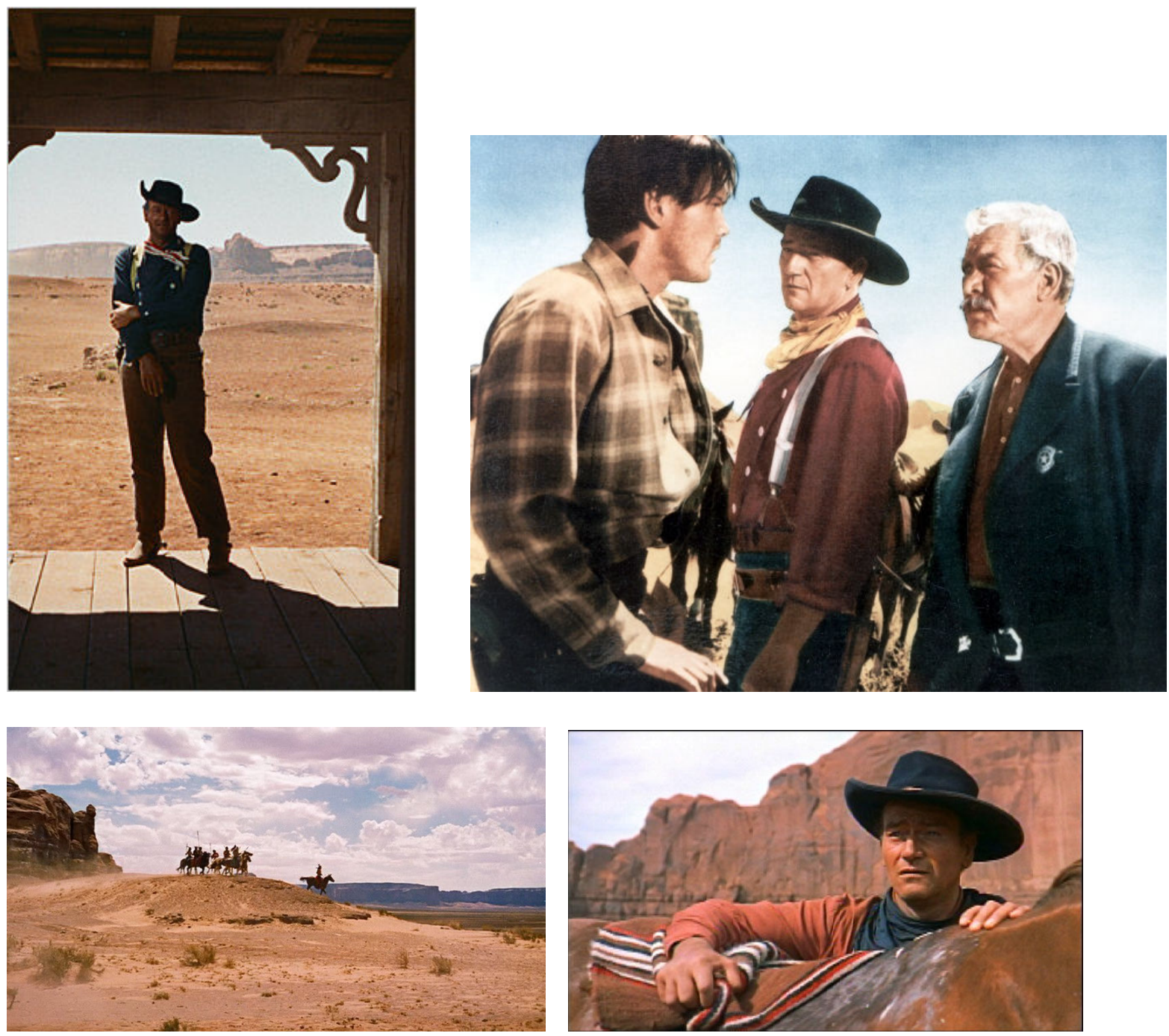